\title{
Gestão democrática do ensino público na educação básica: dimensões comuns e arranjos institucionais sinalizados em bases normativas de sistemas municipais de ensino ${ }^{1}$
}

\section{Democratic administration of public basic education: common dimensions and institutional arrangements shown in regulatory framework of municipal education systems}

\author{
Elton Luiz Nardi*
}

\begin{abstract}
RESUMO
O artigo tem por objetivo analisar um quadro de mecanismos de participação e possíveis arranjos institucionais, patrocinados por sistemas municipais de ensino, para promover a democratização da gestão do ensino público na educação básica. Toma por referência princípios de gestão democrática e mecanismos de participação firmados em bases normativas de sistemas municipais do estado de Santa Catarina, cuja apuração se deu pela via do exame documental, operado no âmbito de uma pesquisa em rede, com vistas ao mapeamento de condições político-institucionais para a promoção da participação e democratização da gestão educacional. As análises permitem realçar dimensões comuns a essas condições, bem como indícios
\end{abstract}

1 Trabalho resultante da pesquisa "Gestão democrática do ensino público: mapeamento das bases normativas e das condições político-institucionais dos sistemas municipais de ensino de Santa Catarina", integrante da Rede MAPA, realizada com o apoio do Conselho Nacional de Desenvolvimento Científico e Tecnológico - CNPq - Brasil (processo 444703/2015-2).

* Universidade do Oeste de Santa Catarina. Joaçaba, Santa Catarina, Brasil. E-mail: elton. nardi@unoesc.edu.br. https://orcid.org/0000-0001-7706-3585 
da configuração de arranjos institucionais com potencial de reforço à democratização da gestão do ensino público em nível de sistema e de escola.

Palavras-chave: Gestão democrática do ensino público. Educação básica. Sistemas municipais de ensino.

\begin{abstract}
This article aims to analyze a participatory framework and possible institutional arrangements, as sponsored by municipal education systems to promote democratization of the administration of public basic education. The basis comes from principles of democratic administration and participatory mechanisms established in regulatory foundations of municipal systems of the state of Santa Catarina, which were verified through documents review, in a network research, in order to map of political-institutional conditions to promote participation and democratization of educational administration. The analyses allow the highlighting of common dimensions to these conditions, as well as setup indications of institutional arrangements with the potential to reinforce democratization of public education administration, at system and at school level.
\end{abstract}

Keywords: Public Education Democratic Administration. Basic education. Municipal Education Systems.

\title{
Introdução
}

No Brasil, temas como participação e deliberação seguem destacados nos debates sobre democracia. Entre outras razões, esse destaque relaciona-se com a própria experiência brasileira que, por um lado, decorreu de transformações políticas ocorridas no final dos anos de 1970 e década de 1980, com o fim do regime militar e os movimentos pela democratização do país; por outro, cultivou uma variedade de canais de participação que, em grande medida, perfilou dinâmicas da relação entre Estado e sociedade como as conhecemos na atualidade.

Todavia, não menos marcantes são as dúvidas e reservas lançadas nesses mesmos debates, quanto ao caráter mais procedimental e menos político de democracia, o que realça o fato de a experiência brasileira caracterizar-se tanto pela inovação e vitalidade como pelo atravessamento de forças que contribuem para seguir tornando a democracia um termo escorregadio. Assim, se pensarmos 
em democracia como um regime que implica na ampla distribuição do poder político entre os membros da comunidade (UGARTE, 2004), é necessário que se atente para certos "erros gramaticais" que também contribuem para gerar erros na prática da democracia (BOVERO, 2000).

O que está no centro da reflexão aqui esboçada é que a participação se vincula estreitamente com a ideia de descentralização do poder, posto ser esta o fator determinante do processo de democratização da ação do Estado e de suas práticas institucionalizadoras (JACOB, 2000). Foi esse o sentido de participação, abraçado pelos movimentos da década de 1980, que a alçaram tanto a condição de recurso para a qualificação da atividade política quanto a de recurso destinado à dissipação de velhas imagens correntes entre nós, como a de que a atividade política é de domínio exclusivo dos políticos tradicionais (NOGUEIRA, 2015).

Ao certo, essas circunstâncias de fundo sobre condições de participação e deliberação no país permeiam os diferentes setores e domínios de atuação do Estado brasileiro, atuação esta também caracterizada pela repartição de encargos entre os entes da Federação ${ }^{2}$, como é o caso da educação.

Acerca dessa repartição, no marco do federalismo brasileiro, importa aqui assinalarmos a incumbência do município de estabelecer, para o seu sistema de ensino, normas de gestão democrática do ensino público consoante o disposto na Constituição Federal de 1988 (artigo 206, inciso VI) e em diretriz infraconstitucional sobre a matéria, fixada na Lei de Diretrizes e Bases da Educação Nacional (LDB), relativamente à educação básica (artigo $3^{\circ}$, inciso VIII).

É, pois, para a resultante dessa incumbência que deslocamos nossas lentes, tendo em vista analisar um quadro de mecanismos de participação e possíveis arranjos institucionais, patrocinados por sistemas municipais de ensino para promover a democratização da gestão do ensino público na educação básica.

As análises ancoram-se nos resultados de pesquisa que visou identificar princípios de gestão democrática e mecanismos de participação firmados em bases normativas de sistemas municipais do estado de Santa Catarina, cuja apuração se deu pela via de exame documental, com vistas ao mapeamento de condições político-institucionais de participação endereçada à democratização da gestão educacional.

2 Cabe registrar que o arranjo federativo vigente, do qual resulta a distribuição de poderes e responsabilidades entre os entes da Federação, consoante o regime de colaboração definido no artigo 211 da Constituição Federal, segue atravessado por contradições e resistências quanto à operacionalização. De acordo com a síntese de Oliveira (2009, p. 23), "uma relação de tensão [gerada no seio da engenharia institucional escolhida para viabilizar o pacto federativo], em grande medida pela insuficiência de recursos financeiros nas unidades federadas [...], limita a autonomia decisória e executiva, indispensável à descentralização democrática." 
Inicialmente, recorremos a alguns aspectos do debate sobre democratização da gestão da educação básica no Brasil, bem como a elementos das bases legais sobre o tema, correlacionando-os à figura do município e seu sistema de ensino. $\mathrm{Na}$ sequência, analisamos o quadro de condições político-institucionais que, formalmente, visam promover a participação destinada à democratização da gestão educacional no âmbito dos sistemas municipais pesquisados.

\section{Gestão da educação: sobre a vaga democrática no contexto brasileiro}

A denúncia de Frigotto de que a política e a gestão educacional em nossa sociedade são produzidas de forma fragmentada e precária, porquanto "expressão das relações sociais dominantes [...] fundada na desigualdade [...]" (FRIGOTTO, 2009 , p. 76), ilustra não somente a complexidade do tema, mas também as condições de se fazer valer um projeto democrático em meio a uma estrutura social desigual. Para Weffort (1984), uma concepção de democracia como instrumento, que decorre diretamente de um privatismo conservador típico em nossa sociedade, sustenta a enorme distância entre o que as intenções proclamam e o que as ações fazem. Isso, segundo o autor, é mesmo o maior mal de uma tradição política que traz a marca da ambiguidade entre democracia e autoritarismo.

Na perspectiva do enfrentamento desse desafio, compartilhamos a ideia de democracia como processo, razão pela qual, seguindo a análise de Coutinho, é de democratização que estamos falando. Essa, por sua vez, só se realiza "na medida em que combina a socialização da participação política com a socialização do poder [...]" (COUTINHO, 2003, p. 17, grifo do autor), em um processo que se choca com a apropriação privada dos mecanismos de poder e, por isso, estampa uma contradição:

o fato de que haja um número cada vez maior de pessoas participando politicamente, participando organizadamente, constituindo-se como sujeitos coletivos, choca-se com a permanência de um Estado apropriado restritamente por um pequeno grupo de pessoas, por membros da classe economicamente dominante ou por uma restrita burocracia a seu serviço (COUTINHO, 2003, p. 17).

E sobre o campo da educação, de que relação com democracia estamos tratando? Neves (2003) propõe que, em razão dos desdobramentos da política 
educacional neoliberal impulsionada nos anos 1990, pensemos essa relação de modo diverso da corrente nos anos 1980, cuja principal bandeira voltava-se à garantia do ensino público, gratuito, universal e de qualidade.

No que designa de caráter antipopular da política neoliberal, entre outras características, a autora refere justamente à participação, mais precisamente ao apelo à participação da sociedade nos destinos da escola pública, então concebida como lócus de síntese do nível gerencial-operacional do sistema. A esse respeito, sublinha que "[...] a participação popular circunscreve-se à defesa de interesses específicos, o que acaba por despolitizar a política, ao impedir o estabelecimento de relações entre as questões de natureza específica com os graves problemas estruturais da nossa sociedade" (NEVES, 2003, p. 171), ${ }^{3}$ solapando o lugar das práticas coletivas de participação social. Shiroma e Campos (2006), ao referirem a desvinculação da ideia de participação como prática de decisão, apontam que a ressignificação da gestão democrática por gestão participativa constitui um dos efeitos mais prejudiciais do atual discurso hegemônico.

Esse patrocínio à despolitização contrasta com os princípios e fins do projeto de democratização da educação escolar defendido pelos movimentos do campo democrático na década de 1980 , do qual a gestão democrática da escola pública é parte, consoante o debate político mais amplo sobre o direito de participação da sociedade civil como condição de uma cidadania ativa (KRAWCZYK, 2008). Segundo Neves (2003), tal cenário nos oferece evidências de que, no século XXI, a discussão sobre democracia e educação escolar, tendo transcendido às questões atinentes ao acesso e permanência das massas trabalhadoras à escola - ainda que se mantenham atuais -, desloca-se aos poucos para a necessidade de "[...] pensar a educação escolar inserida em um projeto democrático de massas de sociedade e de educação [...]" (NEVES, 2003, p. 174).

Como se pode inferir, a participação segue constituindo tema onipresente em discursos políticos, normativos e pedagógicos (LIMA, 2003) e, por razões como as sumarizadas até aqui, continua sendo evocada tanto para realçar a centralidade da intervenção dos sujeitos sociais no espaço público da produção político-educacional (KRAWCZYK, 2008) como para escamotear sua ausência (PARO, 1997).

Do ponto de vista das regras do jogo democrático, importa destacarmos uma vez mais que o artigo 206, inciso VI, da Constituição Federal, firmou o

3 Para a autora, o voluntarismo como a forma de participação alardeada pela política educacional neoliberal "[...] é mais uma faceta da política de despolitização da sociedade, quando práticas coletivas de participação social são substituídas por práticas individualizantes." (NEVES, 2003, p. 172). 
princípio da gestão democrática do ensino público, incorporado ao texto da $\mathrm{LDB}^{4}$ na década seguinte. $\mathrm{O}$ artigo $3^{\circ}$, da lei da educação nacional, fixa que o ensino público será ministrado, dentre outros princípios, com base na "VIII - gestão democrática do ensino público, na forma desta Lei e da legislação dos sistemas de ensino". À noção de democracia vinculam-se, portanto, as de autonomia e descentralização (OLIVEIRA, 2009).

Como extensão dessa determinação, o artigo 14, da LDB, estabelece que a definição, pelos sistemas de ensino, de normas da gestão democrática do ensino público na educação básica deverá estar em conformidade com os princípios da "participação dos profissionais da educação na elaboração do projeto pedagógico da escola" (inciso I) e da "participação das comunidades escolar e local em conselhos escolares ou equivalentes" (inciso II). Também é devido que os sistemas de ensino assegurem às escolas públicas de educação básica, conforme o artigo 15: "progressivos graus de autonomia pedagógica e administrativa e de gestão financeira, observadas as normas gerais de direito financeiro público". A Lei ${ }^{\circ}$ 13.005, de 25 de junho de 2014, que aprovou o Plano Nacional de Educação (PNE) para o decênio 2014-2024, também aponta para essa direção, tendo fixado o prazo de dois anos, contados da publicação da lei, para que os entes subnacionais disciplinassem a gestão democrática no âmbito de seus sistemas de ensino.

Assim, em se tratando do município, ente federativo com responsabilidade de ordenar o desenvolvimento social, importa aqui destacarmos seu papel no estabelecimento de políticas públicas específicas, o que inclui as relacionadas à democratização da gestão do ensino público na educação básica. É o que passamos a abordar, tendo em vista os achados da pesquisa que visou rastrear, no âmbito do quadro normativo tecido por sistemas municipais de ensino, condições político-institucionais de participação da sociedade que respondam ao princípio da gestão democrática do ensino público na educação básica.

\section{Mecanismos de participação em sistemas municipais de ensino: quais condições político-institucionais?}

Nossa leitura acerca das condições político-institucionais de participação, firmadas por municípios catarinenses com vistas à democratização da gestão

4 Vale registrar que, para além da LDB, concorreram iniciativas complementares em escala nacional, destinadas "a assegurar que determinadas opções e práticas endereçadas à democratização da gestão do ensino público adquirissem selo formal.” (NARDI, 2016, p. 485). 
educacional, incidiu sobre uma base legal, composta pela seção das leis orgânicas municipais, que dispõe sobre a Educação, pelas leis que institucionalizaram os sistemas municipais de ensino e por outros atos normativos que, no âmbito dos sistemas, tratam da gestão do ensino público.

Conforme ilustra o Mapa 1,95\% do universo de 295 municípios catarinenses possuem sistemas municipais de ensino institucionalizados, ou seja, optaram por não se integrar ao sistema estadual ou compor com ele um sistema único de educação básica 5 .

\section{MAPA 1 - MUNICÍPIOS DE SANTA CATARINA COM SISTEMAS DE ENSINO INSTITUCIONALIZADOS - 1996 A 2016}

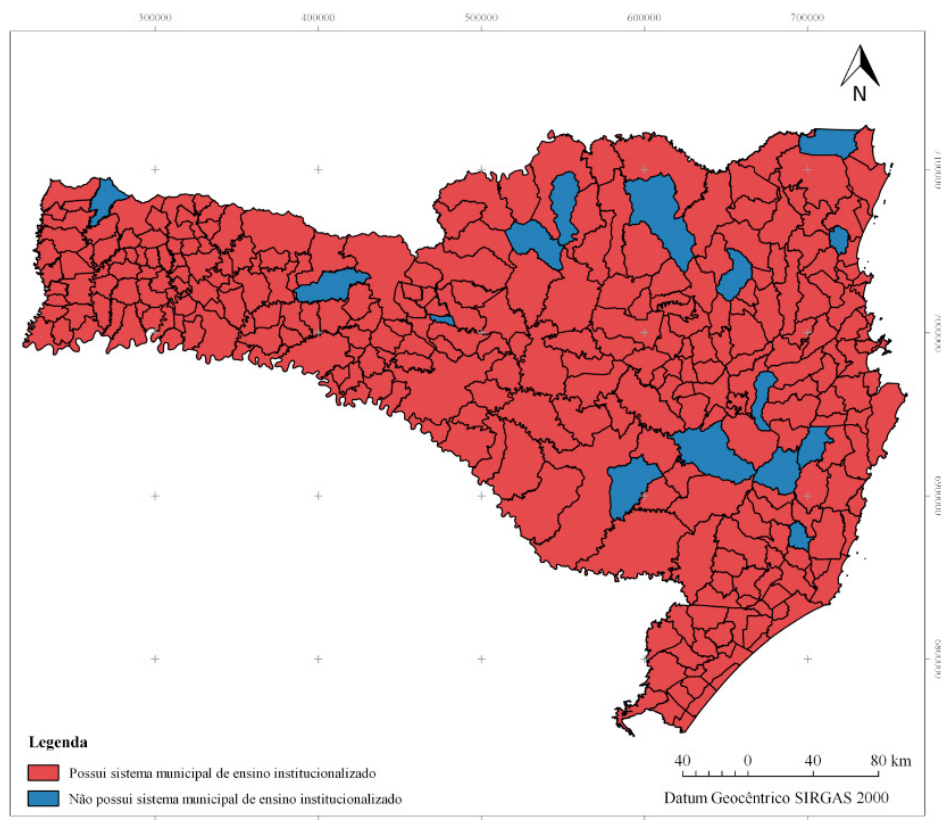

FONTE: elaborado com base em dados da pesquisa Rede Mapa (2017).

Por meio do exame de aproximadamente 1,5 mil documentos de municípios com sistemas próprios de ensino ${ }^{6}$, o levantamento dos mecanismos

5 O ciclo mais intenso de institucionalização dos sistemas ocorreu entre os anos de 1997 e 1999, quando foram aprovadas $42 \%$ das leis municipais que dispõem sobre a matéria.

6 Dos documentos levantados, aproximadamente $36 \%$ correspondem às leis orgânicas municipais e leis de institucionalização dos sistemas municipais de ensino. 
institucionalizados de participação estabelecidos na base normativa foi precedido da identificação, na mesma base documental, dos princípios de gestão democrática. Princípios e mecanismos configuram, portanto, o que denominamos de condições político-institucionais de participação para a democratização da gestão educacional no âmbito dos sistemas municipais.

Enquanto os princípios designam afirmações gerais com base nas quais devem decorrer as demais orientações de ordem legal (ADRIÃO; CAMARGO, 2007) - portanto, disposições fundamentais que se irradiam sobre as normas (SILVA, 2005) -, os mecanismos de participação deliberativa são aqui entendidos como lugares ou instâncias institucionalizadas onde as pessoas deliberam sobre assuntos de interesse público (STRECK; ADAMS, 2006), o que se processa por meio do envolvimento nas atividades desses espaços públicos de deliberação ${ }^{7}$ (CÔRTES, 2007). Ou seja, são lugares onde os sujeitos sociais podem desempenhar ação política em processos decisórios relacionados à identificação de problemas e demandas, acompanhamento, controle, fiscalização e avaliação (LIMA, 2003). De acordo com Bordenave (1985), trata-se do envolvimento na construção da realidade político-social.

Assim, tendo por pressuposto que os mecanismos de participação constituem lugares ou ferramentas destinadas à materialização da gestão democrática do ensino público, consoante princípios formalmente firmados, importa verificarmos, inicialmente, a diversidade e a incidência desses mecanismos em correlação com os princípios igualmente mapeados.

De acordo com os dados apurados, o leque de mecanismos de participação constante da legislação examinada, correlacionado às disposições nucleares informadas pelos princípios, permite-nos apontar ao menos quatro enfoques derivados do repertório coligido, identificados com as ideias de participação e deliberação.

Todavia, se, por um lado, esses enfoques gerais, conforme consta no Quadro 1, derivam fundamentalmente da natureza e da variedade dos mecanismos, na correlação com princípios identificados; por outro, a incidência desses mecanismos e princípios no corpus documental ${ }^{8}$ sugere possibilidades de ocorrência de diferentes significados sociopolíticos nas regras do jogo

7 Conforme observa a autora, se, por um lado, a existência de espaços públicos institucionalizados de participação constitua condição necessária para possibilitar o envolvimento das pessoas nas atividades inerentes a esses espaços; por outro, a constituição de canais de participação não representa garantia de que os participantes envolvam-se de fato nos processos de decisão política. Dentre outras razões, podem escolher não se envolver ou, mediante estratégias manipuladoras, serem levados a um envolvimento pouco efetivo (CÔRTES, 2007).

8 A alta incidência corresponde à presença do mecanismo ou princípio em 66 a 100\% dos sistemas de ensino. Já a incidência média situa-se entre 20 e $36 \%$ e a baixa entre 2 e $17 \%$. 
democrático e, portanto, de diferentes concepções de gestão democrática no âmbito dos sistemas municipais de ensino pesquisados.

\section{QUADRO 1 - CORRELAÇÃO ENTRE MECANISMOS DE PARTICIPAÇÃO E PRINCÍPIOS DE GESTÃO DEMOCRÁTICA CONFORMADOS NA LEGISLAÇÃO DOS SISTEMAS MUNICIPAIS DE ENSINO DE SANTA CATARINA - 1997 A 2016}

\begin{tabular}{|c|c|c|}
\hline Mecanismos de participação & Princípios de gestão democrática & Enfoques \\
\hline $\begin{array}{l}\text { Conselho Municipal de } \\
\text { Educação } \\
\text { Projeto Político-Pedagógico } \\
\text { Conselho Escolar } \\
\text { Eleição de diretores }\end{array}$ & $\begin{array}{l}\text { Participação dos profissionais da educação } \\
\text { na elaboração do projeto político- } \\
\text { pedagógico da escola / Participação dos } \\
\text { profissionais da educação e da comunidade } \\
\text { escolar na elaboração do projeto-político } \\
\text { pedagógico da escola / Participação na } \\
\text { elaboração do projeto político-pedagógico } \\
\text { da rede e das instituições } \\
\text { Progressivos graus de autonomia } \\
\text { pedagógica, administrativa e de gestão } \\
\text { financeira } \\
\text { Participação da comunidade escolar e local } \\
\text { em conselhos escolares ou equivalentes. / } \\
\text { Instituição de conselhos escolares com a } \\
\text { participação da comunidade escolar e local } \\
\text { Transparência dos mecanismos } \\
\text { pedagógicos, administrativos e financeiros. } \\
\text { Descentralização do processo de gestão } \\
\text { educacional e do orçamento } \\
\text { Participação efetiva da comunidade escolar } \\
\text { na tomada de decisões no âmbito das } \\
\text { respectivas unidades escolares e do sistema } \\
\text { municipal de ensino } \\
\text { Escolha de diretores de escola por meio de } \\
\text { eleições } \\
\text { Participação efetiva da comunidade na } \\
\text { escolha de dirigentes escolares }\end{array}$ & $\begin{array}{l}\text { Descentralização do } \\
\text { poder decisório }\end{array}$ \\
\hline Plano Municipal de Educação & $\begin{array}{l}\text { Realização de planejamento educacional } \\
\text { participativo }\end{array}$ & $\begin{array}{l}\text { Definição de } \\
\text { políticas }\end{array}$ \\
\hline $\begin{array}{l}\text { Fórum Municipal de Educação } \\
\text { Conferência Municipal de } \\
\text { Educação } \\
\text { Congresso/Seminário de } \\
\text { Educação }\end{array}$ & Participação na elaboração do orçamento & $\begin{array}{c}\text { Interlocução } \\
\text { sociedade e Estado }\end{array}$ \\
\hline $\begin{array}{l}\text { Associação de Pais e } \\
\text { Professores } \\
\text { Grêmio Estudantil }\end{array}$ & $\begin{array}{l}\text { Autonomia de organização por parte de } \\
\text { pais, professores, servidores e estudantes }\end{array}$ & Articulação política \\
\hline
\end{tabular}

Legenda: Alta incidência

Média incidência

Baixa incidência

FONTE: elaborado com base nos dados da pesquisa Rede Mapa (2017). 
De acordo com o detalhamento constante do Quadro 1, um primeiro conjunto de quatro mecanismos de participação - Conselho Municipal de Educação, Projeto Político-Pedagógico, Conselho Escolar e Eleição de diretores - tem ancoragem em um leque de princípios cujas tônicas são a participação (tendo por referência sujeitos, lugares, decisões e fins), a autonomia e a transparência, de modo a explicitarem um enfoque de participação concernente à descentralização do poder decisório. Quanto à incidência dos mecanismos e princípios filiados a este enfoque, o que retratam os dados permite apontar que, a par do conjunto de mecanismos com alta incidência nas normas dos sistemas de ensino, é igualmente alta a incidência do mandamento acerca da participação de sujeitos, dos lugares de participação e da autonomia. Diferentemente, os princípios cujos mandamentos nucleares dizem respeito a processos decisórios em domínios específicos (como é o caso da eleição de diretores) e à transparência têm baixa incidência nos documentos examinados.

O segundo enfoque diz respeito à participação na definição de políticas. Nesse caso, o exame dos documentos viabilizou identificar, enquanto mecanismo demarcador, o Plano Municipal de Educação, tendo por ordenamento nuclear a realização de planejamento educacional participativo. Também, neste caso, contrasta a alta incidência do mecanismo com a baixa incidência do princípio mais diretamente correspondente.

Já os demais enfoques derivados do repertório normativo remetem, respectivamente, à ideia de interlocução sociedade e Estado e de organização política. Enquanto o primeiro congrega mecanismos como Fórum Municipal de Educação, Conferência Municipal de Educação e Congresso/Seminário de Educação, sob o mandamento nuclear informado pelo princípio da participação na elaboração do orçamento, o segundo enfoque aduz a ideia de participação quanto ao envolvimento político em coletivos de representação de segmentos da comunidade escolar (CÔRTES, 2007). Conforme se observa no Quadro 1, ambos os enfoques têm baixa incidência nos documentos examinados e, portanto, sugerem ocupar lugar periférico na maioria das arquiteturas institucionais do conjunto de sistemas de ensino.

Assim posto, em termos do que vimos denominando de condições político-institucionais de participação, com vistas à democratização da gestão nos sistemas municipais de ensino do estado, os dados permitem verificar um destaque à descentralização do poder decisório, seja pelo repertório de princípios que assistem aos mecanismos de participação, seja pela diversidade e recorrência desses mecanismos. Entretanto, também permitem constatar uma polarização entre este e os demais enfoques identificados - definição de políticas, interlocução sociedade e Estado e organização política -, haja vista que, em 
termos de repertório e recorrência de princípios, estes últimos configuram um quadro de razões diametralmente inverso do destacado no primeiro enfoque.

Então, à luz do pressuposto de que as questões relacionadas à participação constituem o pano de fundo de todos os mecanismos que, de alguma maneira, destinam-se à materialização da gestão democrática do ensino público (MENDONÇA, 2000), entendemos que as condições político-institucionais deslindadas no estudo perspectivam, em primeiro plano, a participação como prática de decisão (SHIROMA; CAMPOS, 2006), embora nuances presentes no mesmo domínio - o normativo - indiciem refreamentos sobre a mesma perspectiva.

\section{Sobre dimensões comuns às condições político-institucionais: notas finais}

Conforme referimos, uma leitura do quadro de mecanismos de participação patrocinado pelo conjunto de sistemas municipais de ensino, determinante de condições político-institucionais formalmente dirigidas à democratização da gestão do ensino público na educação básica, requer considerarmos o desafio de se fazer valer um projeto democrático em uma estrutura social tão desigual como a brasileira. Requer, igualmente, reconhecermos a importância do reforço à participação política das pessoas como sujeitos coletivos, participação esta que se choca com as forças que têm por base uma concepção de democracia meramente instrumental (WEFFORT, 1984).

Rastreados os mecanismos de participação que, em nível de sistemas municipais de ensino de Santa Catarina, encontram-se formalizados a fim de desempenhar ações convergentes com o mandamento constitucional da gestão democrática do ensino público, as análises empreendidas possibilitam apontar, em termos de configuração geral, algumas dimensões comuns às condições político-institucionais levantadas.

Uma primeira dimensão diz respeito ao caráter interdependente que desempenham, por sua natureza, os diferentes mecanismos de participação. Trata-se de uma composição com endereçamentos à gestão em nível de escola e de sistema, fundamentada por princípios que, em geral, respondem a essa mesma lógica.

Em segundo lugar, a relação entre princípios e mecanismos de participação de um mesmo enfoque, excetuados aqueles que dizem respeito a um repertório já tradicional firmado na legislação nacional, como é o caso do Projeto Político- 
Pedagógico, Conselho Escolar e Conselho Municipal de Educação -, tende a ser mais alinhada, em termos de incidência, quanto menos específicos forem os princípios.

Por fim, uma terceira dimensão comum às condições político-institucionais analisadas, e que vem na esteira da dimensão anterior, é a menor incidência, nas normas dos sistemas, de mecanismos que fogem ao espectro dos assim denominados mecanismos fundamentais ou tradicionais, tal como identificados no artigo 14 da LDB (Projeto Político-Pedagógico e Conselho Escolar), no Parecer CEB/CNE n ${ }^{\circ}$ 30/2000 (Conselho Municipal de Educação) e artigo $8^{\circ}$ da Lei no 13.005, de 25 de junho de 2014 (Plano Municipal de Educação).

Em suma, ante as condições político-institucionais de participação aqui examinadas, é devido reconhecer, com base no leque de mecanismos ora conformado em normas dos sistemas de ensino, possibilidades de configuração de arranjos institucionais com potencial de reforço à democratização da gestão do ensino público em nível de sistema e de escola, principalmente em vista do realce à descentralização do poder decisório, fator determinante para um processo de democratização da ação do Estado (JACOB, 2000), e das conexões, traduções e interdependências dos mecanismos, possíveis de serem operadas internamente aos sistemas.

Ao certo, serão os usos efetivos dos mecanismos desses arranjos institucionais que demarcarão a efetividade das ações no campo democrático, devendo estar em causa, por exemplo, como esses mecanismos são recebidos e traduzidos pelos sujeitos sociais enquanto lugares ou ferramentas de participação e decisão. Também, como tal experiência resulta no acionamento de movimentos que se processam de baixo para cima e da periferia para o núcleo (CUNHA, 1981), constituindo formas de enfrentamento de padrões centralistas e de aperfeiçoamento do processo democrático no âmbito dos sistemas municipais de ensino. Sem dúvida, essa é uma frente fundamental para a continuidade das análises sobre a temática em pauta neste trabalho.

\section{REFERÊNCIAS}

ADRIÃO, T. M. de F.; CAMARGO, R. B. de. A gestão democrática na Constituição Federal de 1988. In: OLIVEIRA, R. de; ADRIÃO, T. (Org.). Gestão financiamento e direito à educação: análise da LDB e da Constituição Federal. 2. ed. São Paulo: Xamã, 2007. p. 63-71. 
BRASIL. Constituição da República Federativa do Brasil, 1988. Brasília, DF: Senado Federal, Centro Gráfico, 1998.

BRASIL. Lei n 9.394, de 20 de dezembro de 1996. Estabelece as diretrizes e bases da educação nacional. Diário Oficial [da] República Federativa do Brasil, Poder Executivo, Brasília, DF, 21 dez. 1996. Seção 1, p. 27833-27841.

BRASIL. Conselho Nacional de Educação. Parecer CEB/CNE $n^{\circ}$ 30/2000. Brasília, DF, 2000. Disponível em: <http://portal.mec.gov.br/cne/arquivos/pdf/pceb030_00.pdf $>$. Acesso em: 11 nov. 2017.

BRASIL. Lei n ${ }^{\circ} 13.005$, de 25 de junho de 2014. Aprova o Plano Nacional de Educação - PNE e dá outras providências. Diário Oficial da União, Poder Executivo, Brasília, DF, Edição Extra, nº 120-A, 26 jun. 2014. Seção 1, p. 1-8.

BORDENAVE, J. E. D. O que é participação? São Paulo: Brasiliense, 1985.

BOVERO, M. Contro il governo dei peggiori. Roma-Bari: Laterza, 2000.

COUTINHO, C. N. A democracia na batalha das ideias e nas lutas políticas do Brasil de hoje. In: FÁVERO, O.; SEMERARO, G. (Org.). Democracia e construção do público no pensamento educacional brasileiro. 2. ed. Petrópolis: Vozes, 2003. p. 11-39.

CÔRTES, S. V. Viabilizando a participação em conselhos de política pública municipais: arcabouço institucional, organização do movimento popular e policy communities. In: HOCHAMAN, G.; ARRETCHE, M.; MARQUES, E. (Org.). Politicas públicas no Brasil. Rio de Janeiro: Ed. Fiocruz, 2007. p. 125-143.

CUNHA, L. A. A organização do campo educacional: as conferências de educação. Educação \& Sociedade, Campinas, n. 9, p. 5-48, maio 1981.

FRIGOTTO, G. Política e gestão educacional da contemporaneidade. In: FERREIRA, E. B.; OLIVEIRA, D. A. (Org.). Crise da escola e políticas educativas. Belo Horizonte, 2009. p. 65-80.

JACOB, P. R. Educação, ampliação da cidadania e participação. Educação e Pesquisa, São Paulo, v. 26, n. 2, p. 11-29, jul./dez. 2000.

KRAWCZYK, N. R. Em busca de uma nova governabilidade na educação. In: OLIVEIRA, D. A.; ROSAR, M. de F. F. (Org.). Politica e gestão da educação. 2. ed. Belo Horizonte: Autêntica, 2008. p. 61-74.

NEVES, L. M. W. As massas trabalhadoras começam a participar do banquete, mas o cardápio é escolhido à sua revelia, ou democracia e educação escolar nos anos iniciais do século XXI. In: FÁVERO, O.; SEMERARO, G. (Org.). Democracia e construção do público no pensamento educacional brasileiro. 2. ed. Petrópolis: Vozes, 2003. p. 163-174.

LIMA, L. A escola como organização educativa. 2. ed. São Paulo: Cortez, 2003.

MENDONÇA, E. F. A regra e o jogo: democracia e patrimonialismo na educação brasileira. Campinas: FE/Unicamp, 2000. 
NARDI, E. L. Gestão democrática na educação básica: delineamentos da matéria no pós-LDB. Retratos da Escola, Brasília, DF, v. 10, n. 19, p. 477-492, jul./dez. 2016.

NOGUEIRA, M. A. N. Democracia participativa. In: DI GIOVANNI, G.; NOGUEIRA, M. A. (Org.). Dicionário de políticas públicas. 2. ed. São Paulo: Ed. Unesp; Fundap, 2015. p. 247-252.

OLIVEIRA, D. A. Gestão das políticas públicas educacionais: ação política governance e regulação. In: DOURADO, L. F. Políticas e gestão da educação no Brasil: novos marcos regulatórios? São Paulo: Xamã, 2009. p. 15-29.

PARO, V. H. Gestão democrática da escola pública. São Paulo: Ática, 1997.

SHIROMA, E. O.; CAMPOS, R. F. La ressignificación de la democracia escolar mediante el discurso gerencial: liderazgo, gestión democrática y gestión participativa. In: FELDFEBER, M.; OLIVEIRA, D. A. Politicas educativas y trabajo docente: nuevas regulaciones ¿Nuevos sujetos? Buenos Aires: Noveduc, 2006. p. 221-237.

SILVA, J. A. da. Curso de direito constitucional positivo. São Paulo: Malheiros Editores, 2005.

STRECK, D. R.; ADAMS, T. Lugares da participação e formação da cidadania. Revista de Ciências Sociais, Porto Alegre, v. 6, n. 1, p. 95-117, jan./jun. 2006.

UGARTE, P. S. Que participação para qual democracia? In: COELHO, V. S. P.; NOBRE, M. (Org.). Participação e deliberação: teoria democrática e experiências institucionais no Brasil contemporâneo. São Paulo: Ed. 34, 2004. p. 93-106.

WEFFORT, F. C. Por que democracia? 2. ed. São Paulo: Brasiliense, 1984.

Texto recebido em 18 de janeiro de 2018.

Texto aprovado em 30 de janeiro de 2018. 